\title{
A polymorphism in the nuclear receptor coactivator 7 gene and breast cancer susceptibility
}

\author{
JULIA SÜLLNER ${ }^{*}$, CLAUS LATTRICH ${ }^{*}$, JULIA HÄRING, \\ REGINA GÖRSE, OLAF ORTMANN and OLIVER TREECK
}

Department of Obstetrics and Gynecology, University Medical Center Regensburg, Regensburg, Germany

Received May 9, 2011; Accepted August 24, 2011

DOI: $10.3892 / \mathrm{ol} .2011 .421$

\begin{abstract}
The nuclear receptor coactivator 7 (NCoA7) gene codes for an estrogen receptor-associated protein that plays a significant role in the cellular response to estrogens. Given that NCoA7 is expressed in the mammary gland, alterations in this gene may affect breast cancer risk. In this study, we compared the genotype and allele frequencies of the missense single nucleotide polymorphism (SNP) rs1567, located in the coding region of the $\mathrm{NCoA7}$ gene and resulting in an amino acid exchange from asparagine to glutamine, in 305 women with sporadic breast cancer and 346 women without any malignancy. Statistical analysis of the observed frequencies did not reveal a significant difference between the cancer and control groups, nor did a comparison between histological breast cancer subgroups. In conclusion, the results of our phenotype-genotype association study indicate that $\mathrm{NCoA} 7$ SNP rs1567 does not affect breast cancer susceptibility.
\end{abstract}

\section{Introduction}

Multiple hormone-related mechanisms have been reported to be involved in breast cancer onset and progress (1). Markedly high levels of estrogens are known to increase the risk of developing this disease $(1,2)$. The cellular response to estrogens is mediated by specific estrogen receptors (ERs), ER $\alpha$ and ER $\beta$. These receptors regulate transcription of the target genes by binding directly to estrogen response elements or by interaction with other transcription factors. Binding to coregulatory proteins, which comprise corepressors as well as coactivators, is essential for ER function. These proteins bind to specific domains of the ligand-bound estrogen receptors and are therefore capable of controlling the transcription of

Correspondence to: Dr Oliver Treeck, Department of Obstetrics and Gynecology, University Medical Center Regensburg, Landshuter Str. 65, Regensburg 93053, Germany

E-mail: otreeck@caritasstjosef.de

${ }^{*}$ Contributed equally

Key words: NCoA7, single nucleotide polymorphism, breast cancer target genes (3). In addition to communicating with the transcriptional machinery, certain coregulators are also capable of altering chromatin function (4). It has been suggested that coregulatory proteins perform virtually all of the reactions required to control enhancer-dependent gene expression. These proteins regulate subfunctions of numerous transcription factors in addition to cell processes including translation, energy generation and motility (5).

Nuclear receptor coactivator 7 (NCoA7) is an ER-coactivator protein also known as ERAP140 (ER-associated protein 140) (6). Ligand-bound ER $\alpha$ or ER $\beta$ recruits $\mathrm{NCOA} 7$ to the promoter region of ER target genes (7). Since NCoA7 has little structural homology with other nuclear receptor cofactors, it may represent a distinct class of nuclear receptor coactivators. NCoA7 is expressed in a celland tissue- specific manner. It is most abundantly expressed in the brain, but is also found in organs including the mammary gland, bone marrow, testis, ovary, uterus, prostate, stomach, bladder, spinal chord, pancreas and thyroid (6). The specific physiological function of $\mathrm{NCoA} 7$ is not completely understood. Certain studies have indicated that NCoA7 may be a favourable prognostic indicator for neuroblastomas. On the other hand, other authors identified an isoform that appears to be ovulation-associated and reproduction system-specific; another study found $\mathrm{NCoA} 7$ to possess an activity that contributes to oxidation resistance $(8,9,10)$. Given that NCoA7 is expressed in the mammary gland and thus plays a role in the response of this tissue to estrogens, molecular alterations in the NCoA7 protein may affect breast cancer risk.

The most frequent molecular variations of the DNA are single nucleotide polymorphisms (SNPs). SNPs are point mutations occurring in at least $1 \%$ of the population. SNPs located in exon regions may alter protein function, whereas SNPs in the gene promoter are capable of modifying gene expression levels. Various genome-wide association studies detected a number of gene polymorphisms postulated to influence development of various diseases, as well as breast cancer susceptibility (11-17).

In this study, we tested whether the missense SNP rs1567, located in the last exon of the coding region of the $\mathrm{NCoA} 7$ gene and thus leading to an amino acid exchange from asparagine to glutamine in the coactivator protein, affected breast cancer risk. For this purpose, we performed a genotypephenotype association study and compared genotype and 
allele frequencies of this SNP in 305 women with sporadic breast cancer and 346 without any malignancy.

\section{Patients and methods}

Patients. This study included blood samples from 305 Caucasian women with sporadic breast cancer and 346 age-matched Caucasian women without any malignancy. The median ages of the patient collective and the control group were 55.6 and 54.9 years, respectively (age at diagnosis for case patients and age at inclusion for control subjects). The histopathological characteristics of the patients are shown in Table I. Samples of breast cancer case participants were provided by the Institute of Pathology, University of Regensburg, in an anonymous and randomised manner or were collected at the Clinic of Obstetrics and Gynecology, University Medical Center Regensburg after informed consent was obtained from the patients. Included were Caucasian female sporadic breast cancer patients with available information on tumour size, grading and nodal status, as well as receptor status of ER $\alpha$, PR and HER2, between 2002 and 2007. The control participants originated from the same geographic area as the tumour patients, the Oberpfalz area of Regensburg, Bavaria, Germany. The inclusion criterion for the control subjects was the absence of known malignancies. The study was approved by the Ethics Committee of the University of Regensburg.

SNP analysis. The analysed SNP in the coding region of the last exon in the $\mathrm{NCoA7}$ gene was identified using the websites www.genecards.org and http://www.ncbi.nlm.nih. gov/projects/SNP. SNP rs1567 (G/T) is located at position 126291607 (plus strand) of chromosome 6. The basis for the selection of this SNP was its location in the coding region of the NCoA7 gene. At this position, the nucleotide polymorphism causes a missense mutation and therefore a change of amino acids in the resulting NCoA7 protein. Genomic DNA was isolated from $100 \mu$ l EDTA-blood after the addition of $300 \mu \mathrm{l}$ lysis buffer [1\% v/v TritonX (Sigma, St. Louis, MO, USA), 0.32 M sucrose, $0.01 \mathrm{M}$ Tris (pH 7,5) and $5 \mathrm{mM}$ $\mathrm{MgCl}_{2}$ (Roth, Karslruhe, Germany)] and 2-fold centrifugation $(13000 \mathrm{rpm})$ for $30 \mathrm{sec}$. The pellet was resuspended in $50 \mu \mathrm{l}$ PCR buffer (GoTaq colorless buffer, Promega, Madison, WI, USA) containing $0.5 \%$ Tween-20 (Sigma) and $10 \mathrm{mAnson}$ units proteinase $\mathrm{K}$ (Merck, Darmstadt, Germany), followed by incubation at $50^{\circ} \mathrm{C}$ overnight and heat inactivation of the enzyme for $10 \mathrm{~min}$ at $95^{\circ} \mathrm{C}$. The genomic DNA-containing lysate was subjected to a tetra-primer ARMS PCR approach (18) allowing allele-specific amplification using the PCR primers listed in Table II (synthesised at Metabion, Martinsried, Germany). For this purpose, $2 \mu 1$ of 5X GoTaq buffer, $0.2 \mu \mathrm{l}$ of dNTP mix (10 mM) (Fermentas, St. Leon-Rot, Germany), $0.2 \mu \mathrm{l}$ of primer 567-1, 567-2 and 567-T $(10 \mu \mathrm{M}), 0.4 \mu \mathrm{l}$ of primer $567-\mathrm{G}(10 \mu \mathrm{M})$ and $0.1 \mu \mathrm{l}$ GoTaq polymerase (Promega, Madison, WI, USA) was added to $10 \mathrm{ng}$ of genomic DNA and the PCR reaction was carried out using a T1 thermocycler (Biometra, Goettingen, Germany). The PCR program comprised denaturation of $10 \mathrm{~min}$ at $94^{\circ} \mathrm{C}$ followed by $38 \mathrm{PCR}$ cycles of $94^{\circ} \mathrm{C}(30 \mathrm{sec})$, $63^{\circ} \mathrm{C}(30 \mathrm{sec})$ and anealing at $72^{\circ} \mathrm{C}(60 \mathrm{sec})$, followed by a final extension for $5 \mathrm{~min}$ at $72^{\circ} \mathrm{C}$. PCR products were analysed
Table I. Histopathological characteristics and receptor status of breast cancer cases included in this study $(n=305)$.

\begin{tabular}{lc}
\hline Characteristics & Patient numbers \\
\hline Tumour size & \\
pT1 & 164 \\
pT2 & 107 \\
pT3 & 11 \\
pT4 & 12 \\
pTx & 11 \\
Histological grade & \\
G1 & 10 \\
G2 & 99 \\
G3 & 161 \\
Gx & 35 \\
Nodal status & \\
N0 & 178 \\
N1-3 & 103 \\
Nx & 24 \\
ER $\alpha$ status & \\
Negative $(\leq 4)$ & \\
Positive $(>4)$ & 52 \\
ERx & 243 \\
PR status & 10 \\
Negative $(\leq 4)$ & \\
Positive $(>4)$ & \\
PRx & \\
Her2/neu status & \\
Negative (0-2) & \\
Positive (3) & \\
Her2/neuX & \\
\hline
\end{tabular}

using 1.5\% agarose gel electrophoresis. Allele-specific PCR product sizes for SNP rs1567 were 154/196 bp (G/T). As a quality control for genotyping, a negative water control and a previously characterised DNA sample representing the heterozygous and the two homozygous genotypes were analysed in addition to the unknown samples in each PCR run.

Statistical analysis. Deviation from the Hardy-Weinberg equilibrium was estimated using the Fisher's exact and $\chi^{2}$ tests, and all values were subjected to one-way ANOVA to achieve homogeneity of variance. Statistical tests for association [confidence interval (CI) 95\%] and significance were carried out using Microsoft Office Excel 2003 and the Internet websites http://www.quantitativeskills.com/sisa/ statistics/twoby2.htm and http://ihg2.helmholtz-muenchen.de/ cgi-bin/hw/ hwa1.pl. $\mathrm{P}<0.05$ was considered to be statistically significant. After tests for deviation using the Hardy-Weinberg equilibrium were conducted, allele frequency, allele positivity and genotype frequencies were determined. The odds ratio (OR) was calculated using the more frequent homozygous genotypes as a reference group. 
Table II. Oligonucleotides used for SNP genotyping with tetra primer PCR.

\begin{tabular}{lcc}
\hline SNP & Primer & Sequence (5'-3') \\
\hline rs 1567 & & \\
& $567-\mathrm{T}$ & AGGATCTGGAGGTGTGGGCATTTAAT \\
& $567-\mathrm{G}$ & CAGTCTTTTAATGTTATATTTTAAGGCAGTCTGAATTTAC \\
& $567-1$ & TAGATGCTGATTTATACCACGGACGAAG \\
& $567-2$ & ACCTTCCAGAATCTTTCTGCAATGTGAT \\
PCR product sizes (bp) & & \\
& rs $1567:$ & T allele, 196; G allele, 154; outer primers, 283. \\
\hline
\end{tabular}

Table III. No significant differences were observed between the breast cancer and the control groups with regard to genotype frequency, allele frequency or allele positivity of NCoA7 SNP rs1567 .

\begin{tabular}{|c|c|c|c|c|c|c|c|c|c|c|c|c|c|c|c|c|c|c|}
\hline \multirow{3}{*}{ rs1567 } & \multicolumn{6}{|c|}{ Genotype frequency } & \multicolumn{4}{|c|}{ Allele frequency } & \multicolumn{4}{|c|}{$\begin{array}{l}\text { Allele positivity } \\
\text { for T-allele }\end{array}$} & \multicolumn{4}{|c|}{$\begin{array}{l}\text { Allele positivity } \\
\text { for G-allele }\end{array}$} \\
\hline & \multicolumn{2}{|c|}{ TT } & \multicolumn{2}{|c|}{ TG } & \multicolumn{2}{|c|}{ GG } & \multicolumn{2}{|c|}{$\mathrm{T}$} & \multicolumn{2}{|c|}{ G } & \multicolumn{2}{|c|}{$\mathrm{TT}+\mathrm{TG}$} & \multicolumn{2}{|c|}{ GG } & \multicolumn{2}{|c|}{ TT } & \multicolumn{2}{|c|}{$\mathrm{TG}+\mathrm{GG}$} \\
\hline & $\mathrm{n}$ & $\%$ & $\mathrm{n}$ & $\%$ & $\mathrm{n}$ & $\%$ & $\mathrm{n}$ & $\%$ & $\mathrm{n}$ & $\%$ & $\mathrm{n}$ & $\%$ & $\mathrm{n}$ & $\%$ & $\mathrm{n}$ & $\%$ & $\mathrm{n}$ & $\%$ \\
\hline Case & 229 & 75.1 & 69 & 22.6 & 7 & 2.3 & 527 & 86.4 & 83 & 13.6 & 298 & 97.7 & 7 & 2.3 & 229 & 75.1 & 76 & 24.9 \\
\hline Control & 255 & 73.7 & 81 & 23.4 & 10 & 2.9 & 591 & 85.4 & 101 & 14.6 & 336 & 97.1 & 10 & 2.9 & 255 & 73.7 & 91 & 26.3 \\
\hline P-value & & & & 781 & & 182 & & & 0.6 & & & & 0.6 & & & & 0.6 & 868 \\
\hline Odds ratio & & & & 542 & & 829 & & & 1.0 & & & & & & & & & 753 \\
\hline CI 95\% & & & 0.73 & -1.52 & 0.48 & -3.42 & & & 0.79 & 1.48 & & & 0.75 & 1.53 & & & 0.47 & -3.37 \\
\hline
\end{tabular}

${ }^{a}$ After tests for deviation using the Hardy-Weinberg equilibrium were conducted, genotype and allele frequency were determined, as well as allele positivity. The odds ratio and p-values were determined using the more frequent allele as a reference group. CI, confidence interval.

\section{Results}

Genotype analysis. Analysis of 305 breast cancer patients and 346 women without any malignancy revealed that the homozygous genotype TT of ER-coactivator SNP rs1567 was most frequent $(73.7 \%$ in the control group), whereas the GG genotype was relatively rare (2.3\% in the control group). A heterozygous GT genotype was exhibited by $22.6 \%$ of the control population. Statistical analysis did not show significant differences in homozygous or heterozygous genotype frequencies between the case and the control group (Table III). Thus, no association of a specific rs1567 genotype with breast cancer risk was observed.

Allele frequency. Comparing allele frequencies of the NCoA7 SNP rs1567 in breast cancer patients and controls also showed no significant difference between the two groups (OR 1.0851, Table III). The clearly predominant allele in the two groups was the $\mathrm{T}$ allele ( 0.86 vs. 0.85$)$, whereas only $13.6 \%$ of the tested chromosomes carried the $\mathrm{G}$ allele.

Allele positivity. Phenotype-genotype association analysis of the allele positivity of the rs1567 SNP revealed no significant difference between women with breast cancer and the control population (Table III).
Association between histological breast cancer characteristics and receptor status. We compared SNP genotype frequencies between breast cancer subgroups with various specific tumour characteristics. The respective subgroup size allowed statistical analysis of tumour size (T), nodal status (N) and histological grading $(G)$. No significant difference was observed between the compared subgroups in any of these tests (data not shown). Since interactions between ER $\alpha$, PR, and HER2 occur in breast cancer cells, we also compared the SNP genotypes between the subgroups of different ER $\alpha$, PR and HER2 status. However, statistical analysis did not reveal a significant difference between the receptor status subgroups regarding genotype frequency, allele frequency or allele positivity.

\section{Discussion}

SNPs in genes of steroid hormone metabolism or signalling are potential factors that may affect cancer risk in hormonedependent tissues. Various genome-wide association studies detected a number of gene polymorphisms, which are thought to affect breast cancer susceptibility (14-17). Since estrogens are known to affect breast cancer development, it is essential to analyse polymorphisms in the two estrogen receptor genes, ESR1 and ESR2, as well as their co-regulatory proteins, which may affect breast cancer risk. Co-activators and 
co-suppressors determine the function of ERs as a transcriptional regulator. $\mathrm{NCoA7}$ is an ER coactivator protein that has been shown to be expressed in the mammary gland, but has yet to be analysed in the context of breast cancer.

We did not observe any association of the missense SNP rs1567 with breast cancer risk or with histopathological characteristics of the cancer tissue. Even taking into account the fact that the tested sample numbers were limited and the frequency of the rare genotype was relatively small, the observed allele and genotype frequencies were so similar that our data clearly indicate that NCoA7 SNP rs1567 does not affect breast cancer susceptibility. One explanation for this lack of association is that the missense SNP tested only led to an amino acid exchange from asparagine to glutamine. The two amino acids have markedly similar properties, as they are neutral, polar and hydrophilic amino acids; thus, it appears unlikely that SNP rs1567 was able to strongly alter the structure or function of $\mathrm{NCoA} 7$ protein.

According to previous studies, the NCoA7 protein may be a new group of ER-coactivating proteins (7). Shao et al reported that $\mathrm{NCoA7}$ is a tissue-specific coactivator to agonist-bound nuclear receptors, including the estrogen receptors. These authors also found that $\mathrm{NCoA7}$ is expressed in breast tissue (6). In addition to its role as a coactivator the protein appears to be crucial for the reduction of oxidative damage of the DNA inside the nucleus. The NCoA7 protein contains similar functional domains to the mitochondrial OXR1-protein, which is known to reduce oxidative damage in DNA structure. In contrast to OXR-1, NCoA7 is not stress-induced but reacts to estrogens and interacts with the estrogen receptor (10). Given that NCoA7 is not estrogen receptor-specific but binds to other nuclear receptors as well, this coactivator is involved in a variety of other signalling pathways $(7,19)$.

With regard to the function of NCoA7 in carcinogenesis, only limited data exist. Due to the high expression of NCoA7 in the human brain, previous studies focused on the role of NCoA7 in the context of brain diseases $(8,20)$. NCoA7 expression is reportedly a favorable predictive factor in neuroblastoma (8). To the best of our knowledge, the only NCoA7 SNP study to be published reported a lack of association between the appearance of schizophrenia and five SNPs in this gene (20).

In conclusion, we did not observe any association between NCoA7 polymorphism rs1567 and breast cancer susceptibility. Our results do not preclude a significant function of $\mathrm{NCoA7}$ in breast cancer development.

\section{Acknowledgements}

We thank Helena Lowack for expert technical assistance.

\section{References}

1. Kelsey JL and Bernstein L: Epidemiology and prevention of breast cancer. Annu Rev Public Health 17: 47-67, 1996.

2. Preston-Martin S, Pike MC, Ross RK, Jones PA and Henderson BE: Increased cell division as a cause of human cancer. Cancer Res 50: 7415-7421, 1990.

3. Hall JM and McDonnell DW: Coregulators in nuclear estrogen receptor action - from concept to therapeutic targeting. Mol Interv 5: 343-357, 2005.
4. Silva CM and Shupnik MA: Integration of steroid and growth factor pathways in breast cancer: focus on signal transducers and activators of transcription and their potential role in resistance. Mol Endocrinol 21: 1499-1512, 2007.

5. O'Malley B: Coregulators: From whence came these 'master genes'. Mol Endocrinol 21: 1009-1013, 2007.

6. Shao W, Halachmi S and Brown M: ERAP140, a conserved tissue-specific nuclear receptor coactivator. Mol Cell Biol 22: 3358-3372, 2002

7. Paramanik V and Thakur MK: Interaction of estrogen receptor associated protein (ERAP) 140 with ER beta decreases but its expression increases in aging mouse cerebral cortex. Cell Mol Neurobiol 30: 961-966, 2010

8. Arai $H$, Ozaki $T$, Niizuma $H$, Nakamura $Y$, Ohira $M$, Takano K, Matsumoto M and Nakagawara A: ERAP140/ Nbla10993 is a novel favorable prognostic indicator for neuroblastoma induced in response to retinoic acid. Oncol Rep 19: 1381-1388, 2008.

9. Shkolnik K, Ben-Dor S, Galiani D, Hourvitz A and Dekel N: Molecular characterization and bioinformatics analysis of Ncoa7B, a novel ovulation-associated and reproduction systemspecific Ncoa7 isoform. Reproduction 135: 321-333, 2008.

10. Durand M, Kolpak A, Farrell T, Elliott NA, Shao W, Brown M and Volkert MR: The OXR domain defines a conserved family of eukaryotic oxidation resistance proteins. BMC Cell Biol 8: 13, 2007.

11. Reding KW, Weiss NS, Chen C, Li CI, Carlson CS, Wilkerson HW, Farin FM, Thummel KE, Daling JR and Malone KE: Genetic polymorphisms in the catechol estrogen metabolism pathway and breast cancer risk. Cancer Epidemiol Biomarkers 18: 1461-1467, 2009.

12. Hsieh SM, Smith RA, Lintell NA, Hunter KW and Griffiths LR: Polymorphisms of the SIPA1 gene and sporadic breast cancer susceptibility. BMC Cancer 9: 331, 2009.

13. Giess M, Lattrich C, Springwald A, Goerse R, Ortmann O and Treeck O: GPR30 gene polymorphisms are associated with progesterone receptor status and histopathological characteristics of breast cancer patients. J Steroid Biochem Mol Biol 118: 7-12, 2010.

14. Kirchhoff T, Chen ZQ, Gold B, Pal P, Gaudet MM, Kosarin K, Levine DA, Gregersen P, Spencer S, Harlan M, Robson M, Klein RJ, Hudis CA, Norton L, Dean M and Offit K: The 6q22.33 locus and breast cancer susceptibility. Cancer Epidemiol Biomarkers 18: 2468-2475, 2009.

15. Thomas G, Jacobs KB, Kraft P, et al: A multistage genomewide association study in breast cancer identifies two new risk alleles at 1p11.2 and 14q24.1 (RAD51L1). Nat Genet 41: 579-584, 2009.

16. Zheng W, Long J, Gao YT, et al: Genome-wide association study identifies a new breast cancer susceptibility locus at $6 \mathrm{q} 25.1$. Nat Genet 41: 324-328, 2009.

17. Garcia-Closas M and Chanock S: Genetic susceptibility loci for breast cancer by estrogen receptor status. Clin Cancer Res 14: 8000-8009, 2008.

18. Ye S, Dhillon S, Ke X, Collins AR and Day IN: An efficient procedure for genotyping single nucleotide polymorphisms. Nucleic Acids Res 29: E88-8, 2001.

19. Lazennec G, Ediger TR, Petz LN, Nadulli AM and Katzenellenbogen BS: Mechanistic aspects of estrogen receptor activation probed with constitutively active estrogen receptors: correlations with DNA and coregulator interactions and receptor conformational changes. Molecular Endocrinology 11: 1375-1386, 1997.

20. Liu Y, Shi Y, Guo T et al: No association between the nuclear receptor coactivator 7 gene and schizophrenia in the Chinese Han population. Schizophr Res 89: 360-361, 2007. 